\title{
MOLECULAR DYNAMICS STUDY OF LITHIUM DIFFUSION \\ IN LITHIUM-MANGANESE SPINEL CATHODE MATERIALS
}

$$
\text { SAND- }-97-1642 C
$$

RANDALL T. CYGAN* ${ }^{*}$ HENRY R. WESTRICH*, AND DANIEL H. DOUGHTRECEIVED

${ }^{*}$ * Sandia National Laboratories, Geochemistry Department, Albuquerque, NM 87185-0759 291998 Albuquerque, NM 87185-0613

$$
\text { CONF-97/20/ - OSTI }
$$

\section{ABSTRACT}

A series of molecular dynamics computer simulations of the self-diffusion of lithium in pure and several doped lithium-manganese spinel materials has been completed. The theoretical approach is part of an effort to understand the mechanisms and rates of lithium diffusion, and to evaluate the structural control of the cathode materials upon lithium intercalation (chargedischarge) process. The molecular dynamics approach employs a fully ionic forcefield that accounts for electrostatic, repulsive, and dispersion interactions among all ions. A reference unit cell comprised of 56 ions $\left(\mathrm{Li}_{8} \mathrm{Mn}^{3+}{ }_{8} \mathrm{Mn}^{4+}{ }_{8} \mathrm{O}_{32}\right)$ is used to perform the simulations under constant volume and constant pressure constraints. All atomic positions are allowed to vary during the simulation. Simulations were completed for the undoped and doped $\mathrm{LiMn}_{2} \mathrm{O}_{4}$ at various levels of lithium content (based on the number of lithium ions per unit cell and manganese oxidation state). The molecular dynamics results indicate an activation energy of approximately 97 $\mathrm{kJ} /$ mole for self-diffusion of lithium in the undoped material. Lithium ion trajectories from the simulations provide diffusion coefficients that decrease by a factor of ten as the cathode accumulates lithium ions during discharge. Molecular dynamics results for the doped spinel suggest a decrease in the diffusion rate with increasing dopant ion.

\section{INTRODUCTION}

Molecular modeling and atomic-based energy calculations have recently been used to supplement the synthesis and testing of new oxide materials for lithium ion rechargeable batteries $^{1,2}$. The ability to derive a predictive model is critical to the development of new cathode materials and the improvement of battery performance. Of interest is the investigation of the effects of doping on the crystal chemistry, lattice constants, and electrochemical performance of the lithium manganese oxide spinels ${ }^{3}$. The $\mathrm{LiMn}_{2} \mathrm{O}_{4}$ spinel is one of the best oxide phases for a cathode material, having a voltage plateau of $4 \mathrm{~V}$, a high specific capacity, high thermal stability, low cost, and no or little impact on the environment ${ }^{4}$. Lattice expansion and contraction during, respectively, lithiation and delithiation creates a buildup of stress in the cathode material, and can lead to significant degradation in the battery performance. By providing an atomistic description of lithium ion diffusion through the bulk $\mathrm{LiMn}_{2} \mathrm{O}_{4}$ crystal lattice, a molecular model will be able to evaluate possible diffusion mechanisms, and determine the relative diffusion rates of the lithium for dopant metal and dopant amount, and different levels of lithium intercalation.

Our theoretical approach includes the use of an empirically-derived set of interatomic forcefield parameters to evaluate the stability and crystal structure of pure $\mathrm{LiMn}_{2} \mathrm{O}_{4}$ spinel and several metal-doped derivative compounds. The $\mathrm{LiMn}_{2} \mathrm{O}_{4}$ structure is characterized by a cubic unit cell of 56 atoms $\left(\mathrm{Li}_{8} \mathrm{Mn}^{3+}{ }_{8} \mathrm{Mn}^{4+}{ }_{8} \mathrm{O}_{32}\right)$ and a space group symmetry of $\mathrm{Fd} 3 \mathrm{~m}$. Oxidation of

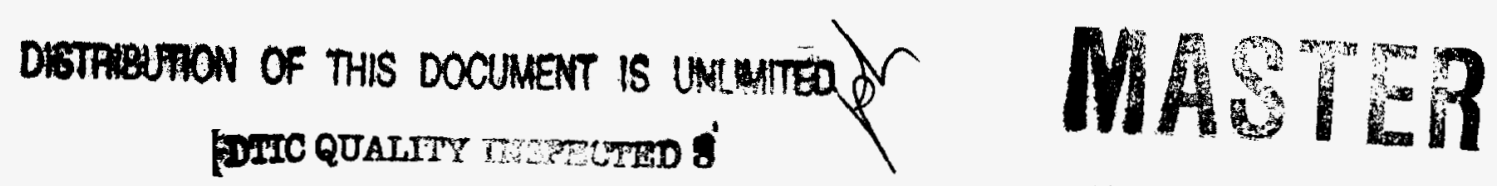




\section{DISCLAIMER}

This report was prepared as an account of work sponsored by an agency of the United States Government. Neither the United States Government nor any agency thereof, nor any of their employees, makes any warranty, express or implied, or assumes any legal liability or responsibility for the accuracy, completeness, or usefulness of any information, apparatus, product, or process disclosed, or represents that its use would not infringe privately owned rights. Reference herein to any specific commercial product, process, or service by trade name, trademark, manufacturer, or otherwise does not necessarily constitute or imply its endorsement, recommendation, or favoring by the United States Government or any agency thereof. The views and opinions of authors expressed herein do not necessarily state or reflect those of the United States Government or any agency thereof. 
Table I. Lennard-Jones energy parameters for ion interactions.

\begin{tabular}{|lrr|}
\hline \multicolumn{1}{|c|}{ Interionic Pair } & $\mathrm{A}\left(\mathrm{kJ} \AA^{12}\right)$ & $\mathrm{B}\left(\mathrm{kJ} \AA^{6}\right)$ \\
\hline \hline $\mathrm{Li}^{+}-\mathrm{O}^{2-}$ & 141382 & 0 \\
$\mathrm{Mn}^{3+}-\mathrm{O}^{2-}$ & 195681 & 13 \\
$\mathrm{Mn}^{4+}-\mathrm{O}^{2-}$ & 525395 & 8728 \\
$\mathrm{Al}^{3+}-\mathrm{O}^{2-}$ & 200700 & 156 \\
$\mathrm{Co}^{2+}-\mathrm{O}^{2-}$ & 719640 & 4863 \\
$\mathrm{Ni}^{2+}-\mathrm{O}^{2-}$ & 385447 & 0 \\
$\mathrm{O}^{2-}-\mathrm{O}^{2-}$ & 4138809 & 2832 \\
\hline
\end{tabular}

the cathode material during battery charging creates the lithium-absent spinel $\lambda-\mathrm{MnO}_{2}$ as lithium ions are transported through the open channels along the [110] direction of the lattice. Conversely, diffusion of lithium back through the channels is important during battery discharge in order to obtain the fully-lithiated and reduced state $\left(\mathrm{LiMn}_{2} \mathrm{O}_{4}\right)$ of the cathode. The reversibility of this process is linked to the fade of the specific capacity and the overall battery performance. A molecular dynamics method is used in this study to evaluate lithium ion diffusion in the pure compound and several doped lithium manganese spinels.

\section{THEORETICAL APPROACH}

The interaction energy $\mathrm{E}$ of two ions is based on the summation of electrostatic, repulsive, and van der Waals (dispersion) energies as a function of the distance $r$ between the ions ${ }^{1}$ :

$$
E\left(r_{i j}\right)=\frac{z_{i} z_{j} e^{2}}{r_{i j}}+\frac{A_{i j}}{r_{i j}^{12}}-\frac{B_{i j}}{r_{i j}^{6}}
$$

The electrostatic term includes the electron charge e and the ionic charge $z$. The interaction parameters A (repulsive) and B (van der Waals) are derived from the observed structures, elastic constants, and dielectric properties of simple binary oxides or from molecular orbital calculations (Table 1$)^{5}$. The total energy of the crystal at $0 \mathrm{~K}$ is obtained by the summation of the interactions of the atoms of a reference cell (usually based on the unit cell) with each other and all ions in the other cells. The summations are carried out partially in reciprocal space in order to achieve

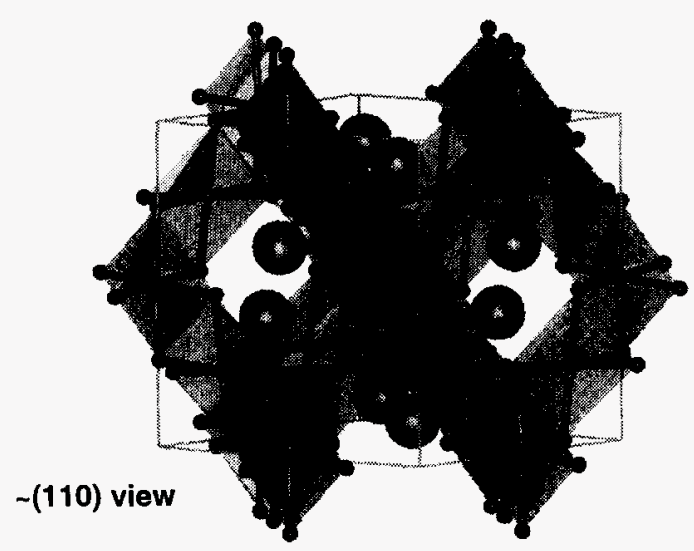

Figure 1. Energy-minimized crystal structure of $\mathrm{LiMn}_{2} \mathrm{O}_{4}$ showing slight distortions in the manganese octahedra and the channels for lithium ion diffusion. 


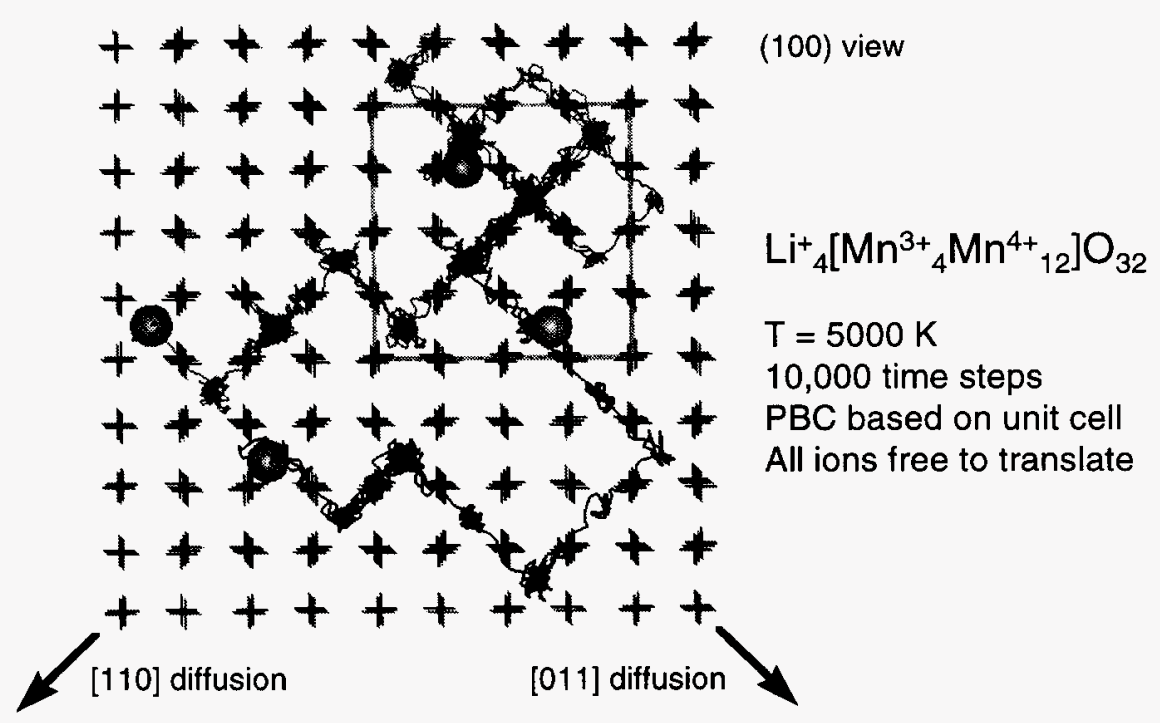

Figure 2. Trajectories of lithium ions from a molecular dynamics simulation of $\mathrm{Li}_{4} \mathrm{Mn}^{3+}{ }_{4} \mathrm{Mn}^{4+}{ }_{12} \mathrm{O}_{32}$ indicating the preferred diffusion path along the (110) directions. The reference unit cell used in the periodic simulation is denoted by the gray outline in the upper right of the lattice.

proper energy convergence. The ionic model assumes a rigid ion approximation by representing each ion as a point or hard sphere of charge; all ions are assigned their full formal charge. Temperature and transient effects are simulated by a molecular dynamics (MD) method. Atomic velocities are initially assigned based on a Boltzmann distribution of thermal energy. The classical equations of motion are then solved for successive time steps to obtain trajectories of atomic motion as the assembly evolves during the simulation.

Energy minimization and MD calculations were performed using the Discover energy program (Molecular Simulations Inc., San Diego) with periodic boundary conditions (PBC). Initial structures of the $\mathrm{LiMn}_{2} \mathrm{O}_{4}$ and doped derivatives are based on the observed structure parameters and asymmetric unit of $\mathrm{LiMn}_{2} \mathrm{O}_{4}{ }^{6}$. A unit cell was generated and then converted to $\mathrm{P} 1$ symmetry, thereby, allowing all atoms to freely translate during each simulation. Doped structures were created by substituting $\mathrm{Al}^{3+}, \mathrm{Co}^{2+}$, or $\mathrm{Ni}^{2+}$ for $\mathrm{Mn}^{3+}$ on the octahedral (16d) site and, if necessary, increasing the amount of $\mathrm{Mn}^{4+}$ to maintain a neutral unit cell. MD simulations were performed for constant volume (NVT ensemble) and constant pressure (NPT ensemble) conditions, and for temperatures of $2000 \mathrm{~K}, 3000 \mathrm{~K}, 4000 \mathrm{~K}$, and $5000 \mathrm{~K}$. Simulations were completed for times up to $30 \mathrm{psec}$ using a one fsec time step. Lithium ion trajectories were monitored after an initial equilibration period of $100 \mathrm{fsec}$, and were obtained for unit cells having one, four, or seven lithium ions. The elevated simulation temperatures are required to ensure statistically significant transport of lithium during the computationally-limited MD calculation.

\section{RESULTS AND DISCUSSION}

The energy-minimized structure of pure $\mathrm{LiMn}_{2} \mathrm{O}_{4}$ obtained from a constant pressure calculation is provided in Figure 1. All of the theoretical cell parameters agree to within $1.5 \%$ of the experimental values. The optimized structure remains cubic and exhibits slight distortions among all of the manganese octahedra. The excellent structural agreement supports the use of the ionic model for simulating the structure and dynamics of the spinel cathode materials and 


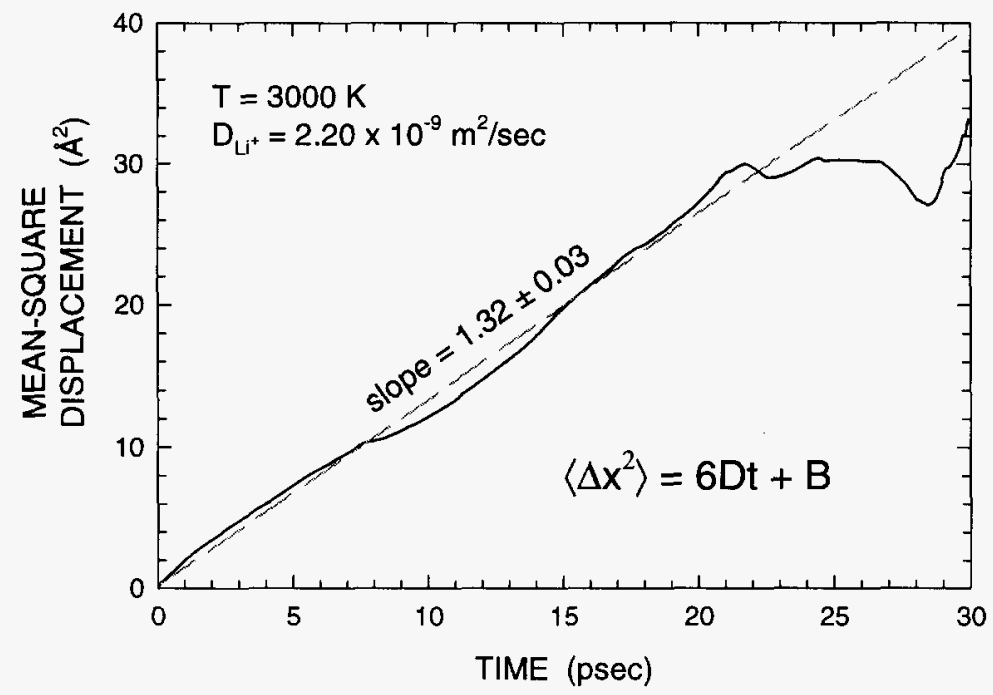

Figure 3. Mean-square displacement as a function of time for all lithium ions from the $3000 \mathrm{~K}$ molecular dynamics simulation of $\mathrm{Li}_{4} \mathrm{Mn}^{3+}{ }_{4} \mathrm{Mn}^{4+}{ }_{12} \mathrm{O}_{32}$. The value for the optimum slope is obtained from a fit to the data from the first $21 \mathrm{psec}$ of the simulation.

underscores the quality of the energy parameters used in describing the ionic interactions.

Figure 2 exhibits the lithium ion trajectories obtained from a $5000 \mathrm{~K} \mathrm{MD}$ simulation of $\mathrm{Li}_{4} \mathrm{Mn}_{16} \mathrm{O}_{32}$ superimposed on a large representation of the initial spinel structure. Although all atoms all allowed to translate, only the lithium ions are energetic enough and are able to overcome the energy barriers between the 8a tetrahedral sites. Lithium diffusion is controlled by the crystallography and occurs preferentially by way of zigzag paths along the family of [110] channels. The integrated mean-square displacement for four lithium ions was calculated as a function of simulation time (Figure 3). The slope of this function is directly related to the selfdiffusion coefficient of lithium. The excursions of the mean-square displacement for this example after $25 \mathrm{psec}$ reflect the transient motion of one or several of the lithiums back toward their original positions. Diffusion coefficients derived from several constant pressure MD simulations are in agreement with the constant volume calculations. Cell parameters vary by less than $2 \%$ and produce a cubic lattice that has cell lengths that are within $1.5 \%$ of those used in the constant volume simulations.

The results of the MD simulations for the pure spinel compound at the various levels of lithium content can be compared in an Arrhenius plot as provided in Figure 4. Calculations for the lowest lithium content $\left(\mathrm{LiMn}^{3+} \mathrm{Mn}^{4+}{ }_{15} \mathrm{O}_{32}\right)$ provide the fastest lithium diffusion coefficients, whereas those for the unit cells with the larger number of lithiums $\left(\mathrm{Li}_{7} \mathrm{Mn}^{3+}{ }_{7} \mathrm{Mn}^{4+}{ }_{9} \mathrm{O}_{32}\right)$ have the slowest rates. This result is related to the availability of vacant tetrahedral sites for diffusion to occur. Of course, no lithium diffusion was observed for MD simulations performed for the fullylithiated (fully-occupied tetrahedral sites) $\mathrm{Li}_{8} \mathrm{Mn}^{3+}{ }_{8} \mathrm{Mn}^{4+}{ }_{8} \mathrm{O}_{32}$ spinel. Activation energies derived from the Arrhenius plot are similar for all the three compositions with a mean value of 97 $\mathrm{kJ} / \mathrm{mole}$. Assuming that the lithium diffusion mechanism remains the same at lower temperatures, the extrapolation of these data to room temperature provides a very slow diffusion rate of $8 \times 10^{-24} \mathrm{~m}^{2} / \mathrm{sec}$. However, the spinel will be subjected to a voltage and redox effects when performing as a cathode in a real battery, and one would expect significantly faster diffusion rates and ionic mobilities. Nonetheless, the pathway for lithium transport will be equivalent and the MD results will provide a convenient test for relative material performance. 


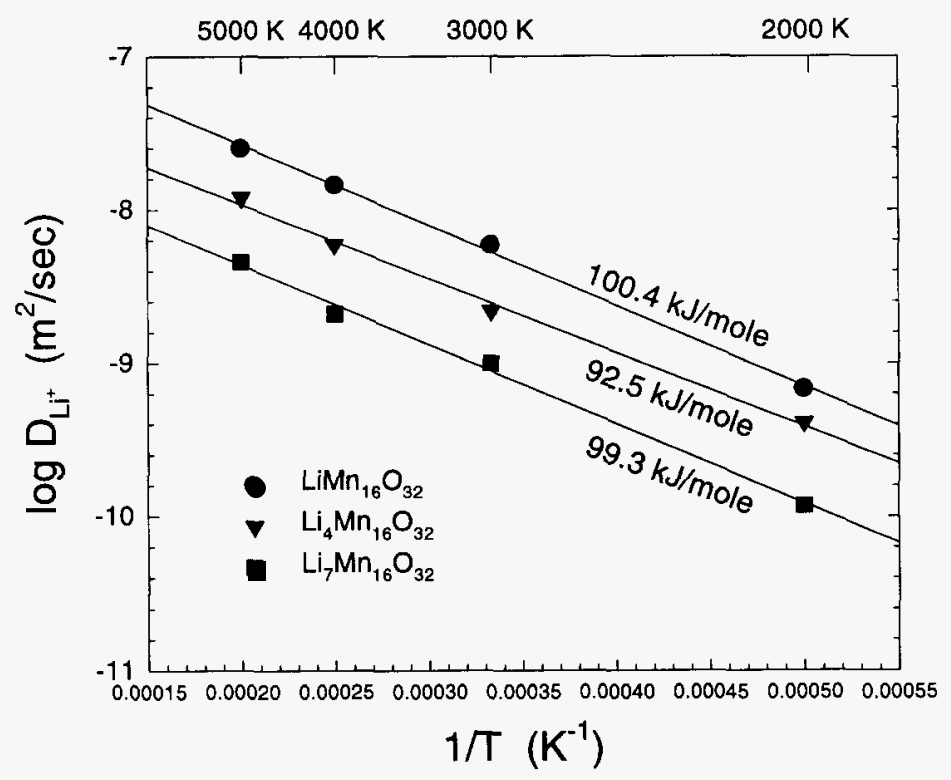

Figure 4. Arrhenius plot of the self-diffusion coefficients for lithium ion in $\mathrm{LiMn}_{2} \mathrm{O}_{4}$ obtained from the molecular dynamics simulations.

MD simulations for the doped $\mathrm{LiMn}_{2} \mathrm{O}_{4}$ compounds suggest a general decrease in lithium diffusion with increasing dopant amount (Figure 5). The doping of the spinel with low amounts of $\mathrm{Co}^{2+}$ and $\mathrm{Ni}^{2+}$ results in lithium diffusion values that are slightly enhanced relative to the pure material but decrease with increasing dopant amount. The faster lithium diffusion rates observed for the single and double-doped $\mathrm{Co}^{2+}$ and $\mathrm{Ni}^{2+}$ spinels are related to the reduced electrostatic interactions associated with the lower-charged metals compared to the $\mathrm{Mn}^{3+}$. Further increases in dopant amounts tend to reduce the diffusion rates. Substitution of a similarly-charged dopant such as $\mathrm{Al}^{3+}$ does not appear to increase the lithium diffusion rate. No significant lattice distortions are observed for the doped spinel materials.

Due to the limitations of the ionic model in performing the MD simulations, the theoretical diffusion coefficients and activation energies can only be interpreted as relative values. Electronic polarization processes have been ignored and can significantly enhance the rates of

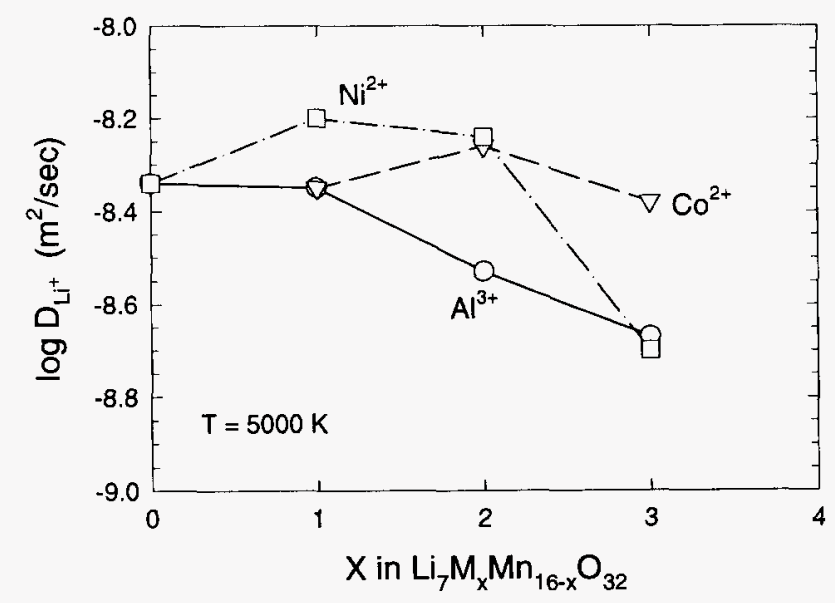

Figure 5. Effect of type and amount of dopant metal on the lithium self-diffusion coefficient as derived from $\mathrm{MD}$ simulations at $5000 \mathrm{~K}$. 
lithium diffusion. Large anions and some polarizable cations are best described by a shell model in which the electronic shell can be shifted away from the atomic core ${ }^{1}$. Future models of the dynamic properties of lithium in the spinel materials would necessarily require this refinement for deriving diffusion coefficients and analyzing the activation energy for lithium migration.

\section{CONCLUSIONS}

The ionic modeling of lithium manganese spinels and their doped derivatives provides a fundamental basis for evaluating the interaction of component ions and predicting their structural and dynamic properties. Results from MD simulations suggest that the lithium self-diffusion coefficient decreases by an order of magnitude during the transition from the oxidized (charged) state to the reduced (discharged) state for the pure $\mathrm{LiMn}_{2} \mathrm{O}_{4}$ cathode. Simulations for the doped spinels indicate a slight increase in lithium diffusion for low levels of divalent metals, however, a general decrease is observed once a dopant level of $13 \%$ is achieved. The theoretical models provide a convenient basis for screening potential dopants and new materials that would be both time-consuming and costly to synthesize and test in the laboratory.

\section{ACKNOWLEDGMENTS}

The authors are appreciative of Tim Boyle, David Ingersoll, Bryan Johnson, Mark Rodriguez, Cory Tafoya, and Jim Voigt for their helpful discussions and comments on the material synthesis and battery testing. Behnam Vessal is gratefully acknowledged for his help in deriving the Lennard-Jones potentials. Suggestions by Diana Fisler, Harlan Stockman, and an anonymous reviewer helped to improve the final manuscript. This work was supported by the U.S. Department of Energy, Office of Basic Energy Sciences, Chemical Sciences Program under contract DE-AC04-94AL85000.

\section{REFERENCES}

1. R.T. Cygan, H.R. Westrich, D.H. Doughty, in Materials for Electrochemical Energy Storage and Conversion-Batteries, Capacitors and Fuel Cells, edited by D.H. Doughty, B. Vyas, T. Takamura, and J.R. Huff, (Mater. Res. Soc. Proc. 393, Pittsburgh, PA, 1995) pp. 113-118.

2. K. Miura, A. Yamada, and M. Tanaka, Electrochim. Acta. 41, 249 (1996).

3. J.A. Voigt, T.J. Boyle, D.H. Doughty, B.A. Hernandez, B.J. Johnson, S.C. Levy, C.J. Tafoya, and M. Rosay, in Materials for Electrochemical Energy Storage and Conversion-Batteries, Capacitors and Fuel Cells, edited by D.H. Doughty, B. Vyas, T. Takamura, and J.R. Huff, (Mater. Res. Soc. Proc. 393, Pittsburgh, PA, 1995) pp. 101-106.

4. L. Xie, D. Fouchard, D., and S. Megahed, in Materials for Electrochemical Energy Storage and Conversion-Batteries, Capacitors and Fuel Cells, edited by D.H. Doughty, B. Vyas, T. Takamura, and J.R. Huff, (Mater. Res. Soc. Proc. 393, Pittsburgh, PA, 1995) pp. 285-304.

5. J. D. Gale, J. Chem. Soc., Faraday Trans., 93, 629 (1997).

6. A. Mosbah, A. Verbaere, and M. Tournoux, Mater. Res. Bull. 18, 1375 (1983). 


\section{M98002577}

| ||||||||||||||||||||||||||||||||||||||||||||||||||||||

Report Number (14)SAND- $-97-1642 \mathrm{C}$

CONF-97/201-

Subl. Date (11) $\frac{199801}{\text { Sponsor Code (18) }}$ WOE/ER, XF
JC Category (19) 